\title{
Erratum to: Preliminary kinetic characterization of a copper amine oxidase from rat liver mitochondria matrix
}

\author{
Roberto Stevanato $\cdot$ Sara Cardillo $\cdot$ Michele Braga $\cdot$ \\ Angela De Iuliis · Valentina Battaglia $\cdot$ Antonio Toninello • \\ Enzo Agostinelli • Fabio Vianello
}

Published online: 17 February 2012

(C) Springer-Verlag 2012

\section{Erratum to: Amino Acids (2011) 40:713-720 \\ DOI 10.1007/s00726-010-0708-y}

Unfortunately, Table 1 of the original article was published with errors. Some of the signs of electrical charges of terminal amino groups of polyamines had negative charges instead of positive charges. The correct version of Table 1 is produced here.

The correct affiliation of Enzo Agostinelli is given below:

Istituto Pasteur-Fondazione Cenci Bolognetti, Department of Biochemical Sciences, SAPIENZA University of Rome and CNR, Institute Biology and Molecular Pathology, Piazzale Aldo Moro 5, 00185 Rome, Italy.

The online version of the original article can be found under doi: 10.1007/s00726-010-0708-y.

S. Cardillo $\cdot$ M. Braga $\cdot$ V. Battaglia $\cdot$ A. Toninello .

F. Vianello (ه)

Department of Biological Chemistry, University of Padua,

Viale G. Colombo 3, 35121 Padua, Italy

e-mail: fabio.vianello@unipd.it

A. De Iuliis

Department of Medical Sciences,

University of Padua, 35121 Padua, Italy

R. Stevanato

Department of Physical Chemistry, University of Venice,

“Ca' Foscari', Dorsoduro 2137, 30123 Venice, Italy

E. Agostinelli

Istituto Pasteur-Fondazione Cenci Bolognetti,

Department of Biochemical Sciences, SAPIENZA University

of Rome and CNR, Institute Biology and Molecular Pathology,

Piazzale Aldo Moro 5, 00185 Rome, Italy
Table 1 Structure and chain length of amines used as MMAO substrates

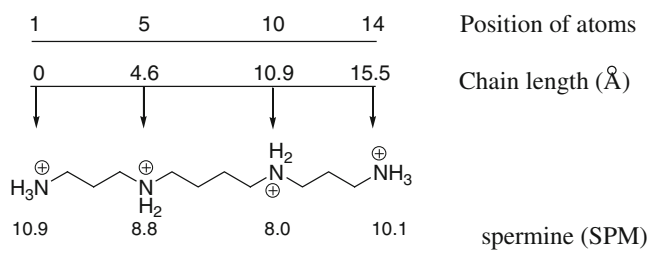

1,12-diaminododecane

$\mathrm{H}_{3} \mathrm{P}^{\oplus} \overbrace{4,9-d i o x a-1,12-d i a m i n o d o d e c a n e}^{\stackrel{\oplus}{N} \mathrm{H}_{3}}$<smiles>NCCCCNCCCC[NH3+]</smiles>

spermidine (SPD)<smiles>[NH3+]CCCCCCCCC[OH2+]</smiles>

1,8-diamino-octane<smiles>CCCCCCCCCCCCCC</smiles>

10.6

1-aminononane<smiles>CCCC[NH3+]</smiles>

1-aminobutane<smiles>[NH3+]CCC[NH3+]</smiles>

1,3-diamino-propane<smiles>[NH3+]CCCC[Hg]</smiles>

1,4-diamino-butane (PUT)<smiles>COc1ccccc1</smiles>

benzylamine 